\title{
BMJ Open Cohort profile: social well-being and determinants of health study (SWADES), Kerala, India
}

\begin{abstract}
Saju M D (D) ,1,2 Lovakanth Nukala, ${ }^{3}$ Rameela Shekhar, ${ }^{4}$ Keith Gomez, ${ }^{5}$ Bindiya M Varghese, ${ }^{2}$ Anuja Maria Benny, ${ }^{2}$ Lorane Scaria, ${ }^{2}$ Sphoorthi Prabhu, ${ }^{6}$ Amuthavalli Thiyagarajan Jotheeswaran ${ }^{7,8}$
\end{abstract}

\section{To cite: M D S, Nukala L, Shekhar $\mathrm{R}$, et al. Cohort profile: social well-being and determinants of health study (SWADES), Kerala, India. BMJ Open 2020;10:e032803. doi:10.1136/ bmjopen-2019-032803 \\ - Prepublication history and additional material for this paper are available online. To view these files, please visit the journal online (http://dx.doi. org/10.1136/bmjopen-2019- 032803).}

Received 09 July 2019 Revised 12 December 2019 Accepted 12 February 2020

A Check for updates

(c) Author(s) (or their employer(s)) 2020. Re-use permitted under CC BY-NC. No commercial re-use. See rights and permissions. Published by BMJ.

For numbered affiliations see end of article.

Correspondence to

Dr Saju M D; saju@rajagiri.edu

\section{ABSTRACT}

Purpose In response to the need for more advanced and longitudinal data concerning chronic diseases, behavioural risk factors and social support systems in India, the SWADES (Social Well-being and Determinants of Health Study) was established.

Participants At baseline, 997 adults aged 30 years and over, living in the semi-urban area were interviewed in their home.

Findings to date Data collected included self-reports of demographic details, health, depression, morbid conditions and healthcare utilisation, risk factors (physical, behavioural and social) of chronic diseases, common mental disorders, out-of-pocket expenditure, social support network, social cohesion, disability, education and wealth. Objective data for hypertension, diabetes and cognitive function were also collected.

Future plans The first annual follow-up interviews were completed in 2019; the subsequent annual follow-up will be conducted until 2030. The SWADES data are held at the International Centre for Consortium Research in Social Care (ICRS), Rajagiri College of Social Science, Kerala, India. Procedures for data access, information on collaborations, publications and other details can be found at (http://icrs.in).

\section{INTRODUCTION}

In the last 70 years, India has achieved a massive improvement in the life expectancy of the population. ${ }^{1}$ On average, a child born during independence in 1947 was expected to live up to 31 years, but today the life expectancy at birth is nearly 70 years. While this twofold increase suggests that people are living longer, the corroborating evidence indicates that not all are experiencing good health.

In 2017, the Global Burden of Disease study estimated that non-communicable diseases (NCDs) were the leading cause of premature death and disability in India. ${ }^{23}$ Between 1990 and 2017, the years of healthy life lost due to NCDs increased staggeringly, from $30.5 \%$ to $55.4 \%$ in India. More specifically, cardiovascular diseases and diabetes increased more than two-fold. ${ }^{4}$ Besides population growth

\section{Strengths and limitations of the study}

- The major strength of the study is the longitudinal study design that facilitates investigation of intergenerational exposure to chronic diseases risk and incidence.

- This cohort study over a period of 10 years explores and predicts the causation of a range of biopsychosocial factors leading to cardiovascular risk among community population.

- The study uses a set of validated instruments in measuring the specified variables assessing the various risk factors through well-trained interviewers.

- The findings of the study will inform the development of a comprehensive multicomponent intervention to manage cardiovascular disease risk in community populations that may have potential policy implications.

- This however is not a representative population of Kerala, thus limiting the generalisability of findings over the entire state.

and ageing, changes in the burden of disease over time are the result of changes in the three underlying risk factors: (1) changes in exposure to environmental risks, including social environment; (2) changes in exposure to behavioural risks and (3) changes in exposure to metabolic risks.

While studies in recent years have begun to investigate the intergenerational association between exposure and disease, little research has been carried out (to date) in India on the long-term biological, behavioural, psychological, social and environmental mechanisms that link range of risk factors and chronic non-communicable diseases to exposures acting across generations. Furthermore, existing population-based studies in Kerala measure the effect of risk factors on NCDs by calculating relative risk and ORs. These measures of risk are difficult to apply at an individual level because an individual may have hypertension or diabetes without any 
exposure to risk factors or may be exposed to multiple risk factors at various exposure levels.

Therefore, for administering community-based interventions, absolute disease and managing risk should be estimated for each individual in the community. The development of risk prediction models using community cohort is a very active area of research where survey findings can be applied to predict an individual's future risk for NCDs as well as adherence to treatment.

In Kerala, the loss of healthy life due to high blood pressure and high blood glucose is closer to the average estimates of India. ${ }^{4}$ However, the efforts to monitor, prevent and reduce risk factors of NCDs have been mainly at the peripheral level, such as mass screening programme and media campaigns for smoking cessation and reducing alcohol intake, encouraging healthy diet and exercise. Although this kind of population-based approach has a significant impact, personalised health and social care that assess individuals risk and administer preventive strategies at individual and family level are currently underprioritised. Such effort is quintessential not just to downsize the detrimental effect of NCD, but also improve the health and well-being of the population. Therefore, a population-based cohort infrastructure was established in Kerala to monitor physical, social and behavioural risk factors that escalate incidence of chronic diseases as well as poor treatment adherence, health illiteracy, disability and mental health comorbidities. This cohort profile elucidates details about the SWADES (SocialWell-being and Determinants of Health Study) household survey, which aims at monitoring and addressing the risk factors of chronic disease in the adult population aged 30 years and over.

\section{Potential implications for service planning and interventions development}

Health services in low- and middle-income countries are typically organised around a specific health problem and interventions to address the risk factors mostly occur in isolation, targeting a single chronic condition rather than focussing on the social fabric which underpins the behavioural risk factors and their association to multiple conditions. ${ }^{5}$ The health service fragmentation requires people with complex care needs to visit separate specialists with little communication between providers, potentially resulting in different diagnoses, treatment and management plans from physical and mental health services. In resource-poor settings, 'task shifting' away from specialist care toward a model in which frontline care is provided by the community or lay health workers (CHW) has become an important and cost-effective strategy to manage chronic conditions. ${ }^{6}$ Currently missing from the literature on task shifting is the opportunity to train a workforce in addressing the underlying social and behavioural causes of chronic diseases that run across the fragmented services. The effective management of these chronic conditions requires a collaborative effort across the health and social care workforce. ${ }^{7}$
In India, medical and psychiatric social workers are trained to support people with physical and mental health problems to access social welfare. With critical skills in connecting individuals, organisations and the acquisition of community resources, social workers may be uniquely positioned to support an integrated service-level care model. ${ }^{8}$ Service delivery integration occurs at three levels: linking of fragmented services to facilitate referral and collaboration to manage users' needs, coordination of an umbrella system under which health and social care services operate and full integration of a single virtual organisation responsible for all services. In this study, the focus is on the integration of services through mobile applications. We intend to evaluate the feasibility of integrating medical and psychiatric social workers alongside existing CHWs. This project aims to develop a technological platform assisted by a mobile application to assess, link and monitor the vitals of the persons and patterns of treatment in connection with treatment adherence and medical compliance.

\section{What does SWADES cover?}

The objectives of the SWADES cohort study are: (a) to monitor changes over time in physical, behavioural and social risk factors associated with chronic diseases and mental health comorbid conditions, (b) to develop chronic disease risk prediction models and estimate the probability of having or developing a particular chronic disease within a specific period and (c) to scale-up population and family health interventions and evaluate their impact.

\section{COHORT DESCRIPTION}

The SWADES is a population-based family cohort of men and women who resided in Kerala and were aged 30 years and over as on 30 April 2018. All members of a family fulfilling age criteria were enrolled and followed-up. The participants were identified through a door-to-door survey conducted in 2018. In the follow-up, additional eligible members in the families were also recruited(See figure 1). The study was conducted in geographically well-defined catchment areas which represent the mixed culture and social, economical characteristics of Kerala population in India. Participation was based on signed informed consent. The study catchment area is located in the semi-rural region of Keezhmadu panchayat in Ernakulam, Kerala, India. In 2018, the catchment area boundaries were precisely defined. A mapping exercise was carried out to identify and locate all households with at least one eligible participant. Age (and therefore eligibility) was formally determined on revisit for interview. For each household, gender and age of all residents were recorded with the names of those aged 30 years or over on the census date. Since the participants have been identified from the same community and since the participants belong to age group 30 years and above, it is expected that the loss to follow-up will be very minimal. Although, 


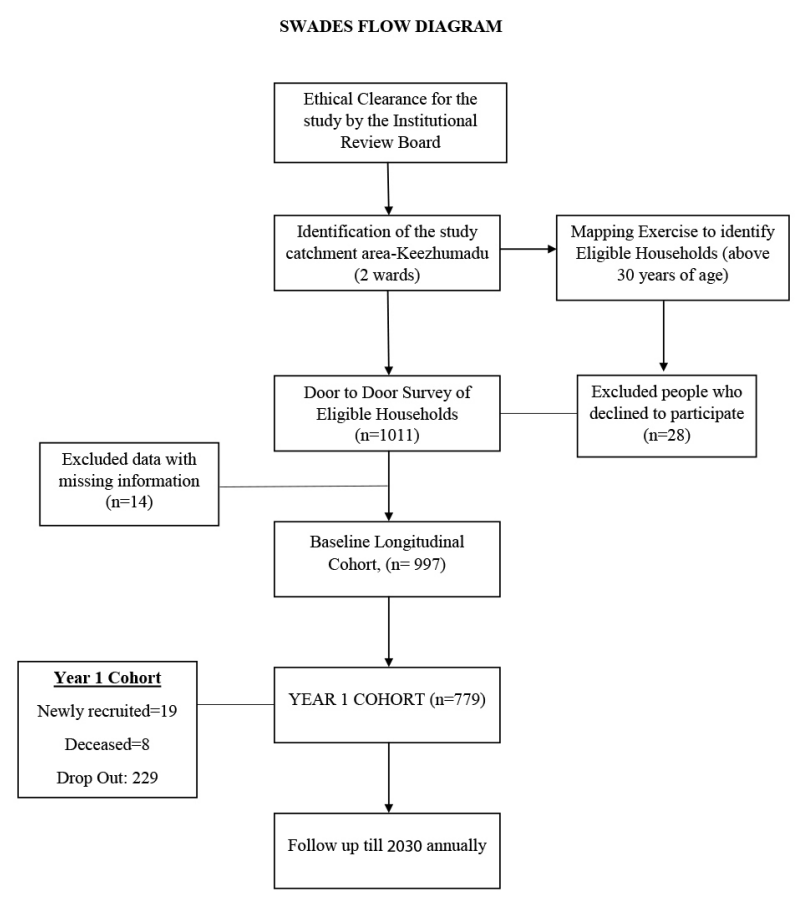

Figure 1 Flow diagram.

the study is for long duration the chances for the study effecting the participant's behaviour is limited, as the participants are blinded to the expected outcomes. Moreover, the risk factor exposures being measured belong to wide range including sociodemographic features, in addition to health. However, the participants behaviour may change owing to the participants gaining awareness and beginning to implement preventive health behaviour which may have an effect on the outcomes. Any changes in participants behaviour may also be captured during the annual follow-up of participants.

Household and participant details were stored in secure databases. These contained names, addresses, ID numbers and contact details of the key informants for potential follow-up. The baseline interviews with participants were conducted in 2018, and the first annual follow-up was completed in 2019. All family members recruited in the baseline and eligible members, including new residence identified in the follow-up will be revisited annually for structured interview till 2030.

\section{Patient and public involvement}

Patients and/or the public were involved in the design, or conduct, or reporting or dissemination plans of this research.

\section{Socioeconomic and health charateristics}

The socioeconomic charateristics of study participants are described in table 1 . Mean age of the participants was 53.9 (14.2) and majority of them were female, married and residing in nuclear family. About less than one-fourth completed higher education and majority of them were in lowest income quartile. More than one-third of the participants were diagnosed as having diabetes or hypertension.
Table 1 Demographic,socioeconomic and health characteristics of the sample

\begin{tabular}{|c|c|}
\hline Variable & Total $(n=997)$ \\
\hline \multicolumn{2}{|l|}{ Age groups } \\
\hline $30-40$ & $203(20.36 \%)$ \\
\hline $40-50$ & $202(20.26 \%)$ \\
\hline $50-60$ & $223(22.37 \%)$ \\
\hline $60-70$ & $228(22.87 \%)$ \\
\hline $70+$ & $141(14.14 \%)$ \\
\hline \multicolumn{2}{|l|}{ Sex } \\
\hline Male & $365(36.6 \%)$ \\
\hline Female & $632(63.39 \%)$ \\
\hline \multicolumn{2}{|l|}{ Marital status } \\
\hline Unmarried & $18(1.81 \%)$ \\
\hline Married/cohabiting & $824(82.65 \%)$ \\
\hline Widowed/divorced/separated & $155(15.55 \%)$ \\
\hline \multicolumn{2}{|l|}{ Education } \\
\hline No formal education & $41(4.11 \%)$ \\
\hline Primary education & $538(53.96 \%)$ \\
\hline Secondary education & $216(21.66)$ \\
\hline Above secondary & $202(20.26 \%)$ \\
\hline \multicolumn{2}{|l|}{ Born } \\
\hline Town & $77(2.91 \%)$ \\
\hline City & $29(7.72 \%)$ \\
\hline Village & $891(89.37 \%)$ \\
\hline \multicolumn{2}{|l|}{ Religion } \\
\hline Christian & $248(24.87 \%)$ \\
\hline Hindu & $322(32.30 \%)$ \\
\hline Muslim & $427(42.83 \%)$ \\
\hline \multicolumn{2}{|l|}{ Type of family } \\
\hline Alone & $11(1.10 \%)$ \\
\hline Nuclear family & $607(60.88 \%)$ \\
\hline Extended family & $312(31.29 \%)$ \\
\hline Mixed family & $67(6.72 \%)$ \\
\hline \multicolumn{2}{|l|}{ Occupation } \\
\hline Unemployed & $239(23.97 \%)$ \\
\hline Paid work & 341 (34.20\%) \\
\hline Housewife/husband & $337(33.80 \%)$ \\
\hline Retired & $80(8.02 \%)$ \\
\hline \multicolumn{2}{|l|}{ Income } \\
\hline Quartile 1 & $417(41.83 \%)$ \\
\hline Quartile 2 & $108(10.83 \%)$ \\
\hline Quartile 3 & 245 (24.57\%) \\
\hline Quartile 4 & $227(22.77 \%)$ \\
\hline \multicolumn{2}{|l|}{ Health conditions } \\
\hline Diabetes & $259(26.0 \%)$ \\
\hline Hypertension & 333 (33.40\%) \\
\hline
\end{tabular}

Continued 


\begin{tabular}{lc}
\hline Table 1 Continued & \\
\hline Variable & Total $(\mathbf{n = 9 9 7 )}$ \\
\hline Stroke & $24(2.40 \%)$ \\
Heart diseases & $102(10.20 \%)$ \\
Transient ischaemic attack & $106(10.60 \%)$ \\
Tuberculosis & $11(1.10 \%)$
\end{tabular}

\section{Patient involvement}

No patients were involved in the development of the research question, study design or interpretation of the data in this study

\section{Data linkage: geospatial information}

Geographical latitude and longitude associated with each datum are captured using the android application developed specifically for the SWADES study. Another feature associated with the application is to capture a real-time image of the concerned household and the locations of different community resources. Map indicating the location of participants included in the study is depicted in figure 2. The captured data was collected and stored in the central repository to analyse it further.

A new Android application was developed by the team to capture geospatial data of each household under the study. Real-time data was collected about formal and informal community resources; to assess the needs, planning the service delivery, to identify the pattern of human networking, social capital and social cohesion. The purpose of Android application was also to plan emergency response in the event of health issues and illustrate closeness to health service centres, community power centres, utility centres such as provision shops, ration shops, grocery shops and medical shops. Besides, the application also was developed to map the public transportation facilities and other accesses.

\section{What has been measured?}

Interviews were carried out in participants' own homes. This was a comprehensive one phase survey-all participants received the full assessment, lasting approximately $45 \mathrm{~min}$. All interviewers were extensively trained in primary assessments (see below) for hypertension and diabetes. Two further 1-week project planning meetings were held with all interviewers, project coordination team and the investigators. A standard operating procedure manual covering every aspect of the training and field procedures ensured uniformity. Information about principal exposures was elicited from participants; with informants also interviewed for those with communication difficulties arising from dementia, severe mental illness, deafness or severe hearing impairment. We used core minimum data set with cross-culturally validated assessments (mental conditions, physical health, demographics, extensive non-communicable disease risk factor questionnaires, disability/functioning and health service utilisation). All study instruments were translated, back-translated and assessed for acceptability and conceptual equivalence. Translations were done locally, by investigators fluent in English (the language of the instruments) and the local language (Malayalam) to be used in the study. The translated version was reviewed by a group of independent experts with specialised local language. All measures pertaining to sociodemographic, physical, mental, functional, social cohesion, social support networks, behavioural risk factors, health services utilisation, cognitive function and risk of fall; have been measured using respective scales or risk assessment tools limiting the effect of confounding factors within the measures.

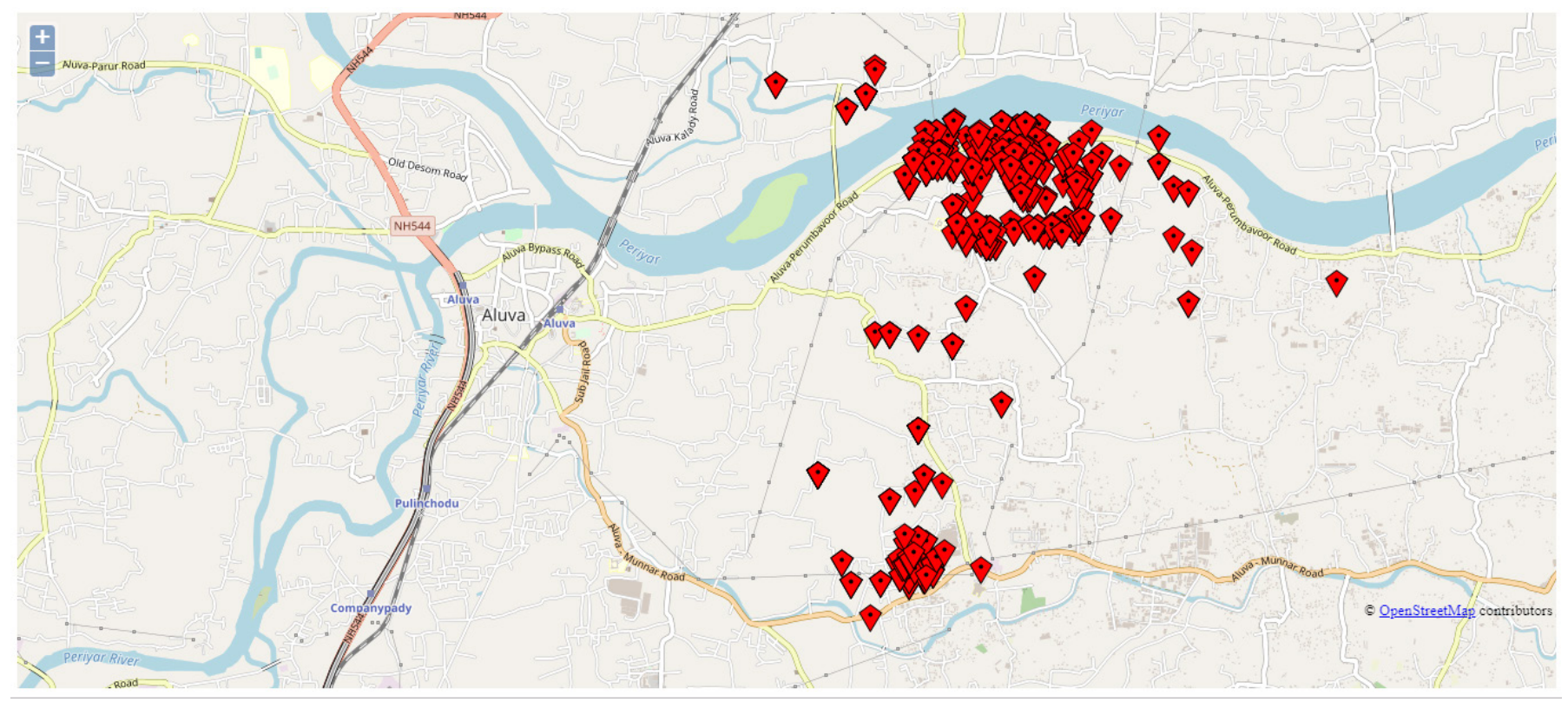

Figure 2 Smart application interface screen image indicating ward-wise distribution of the cohort. 


\section{Measures of sociodemographic factors}

Age was determined at the interview from participant report, informant report, documented age, or an event calendar. Area of residence was recorded as city, town and village. Education level was ascertained, and coded as: no education did not complete primary, completed primary, completed secondary and completed tertiary education. Literacy was recorded in terms of ability to read and write in the local language. We also recorded sex, marital status (single/divorced/widowed or married/cohabitating), current occupational status (no job, full-time and parttime paid job, housewife/husband, unemployed looking for job, retired), monthly income, socioeconomic class (based on colour of ration card), religion affiliation and practice.

\section{Measures of physical health}

Self-reported diagnoses (stroke, diabetes, hypertension, heart disease, tuberculosis, malaria and others) and treatments for these conditions. Objective measurements of diabetes and hypertension were recorded from the participants from their home. Three measurements of blood pressure were obtained using a blood pressure monitor. Three (two sitting and one standing) blood pressure measurements were obtained to measure the blood pressure. ${ }^{9}$ Random glucose measurements were obtained using a glucometer. Blood glucose level was measured by obtaining a blood sample by pricking the person's fingertip using a lancet. ${ }^{10}$ All interviewers were adequately trained on the administration of these devices. Factors like genetic predisposition or family history of diabetes and hypertension may have confounding effect. However, since the study is targeted to measure the social dimensions and risks of diabetes and hypertension and the study is for a relatively long duration, it is expected that the effects of these confounders will be very limited. Since the exposure categories have already been established in the communities based on the initial responses identified, the movement of participants from one exposure category to the other can be controlled from the beginning. However, if in future a participant belonging to one exposure category also develops risk factors of another exposure category, the original exposure category of the participant can always be traced back to the initial data already collected. The risk factor exposure status and the outcomes classification has already been established from the beginning of the study. The details pertaining to the risk factor exposure status and outcomes (hypertension and diabetes) have also been mapped to each of the participants, therefore, limiting this bias.

\section{Measures of mental health}

Depression and anxiety were assessed using the selfreport Depression, Anxiety and Stress Scale (DASS). DASS is a set of three scales which separately measure depression, anxiety and stress. Participants were asked to use 4-point severity/frequency scales to rate the extent to which they experienced each state over the past week.
Scores for depression, anxiety and stress were calculated by summing the scores for the relevant items. Gamma coefficients that represent the loading of each scale on the overall factor (total score) are 0.71 for depression, 0.86 for anxiety and 0.88 for stress. ${ }^{11}$ Reliability of the three scales is considered adequate, and test-retest reliability is likewise considered good with 0.71 for depression, 0.79 for anxiety and 0.81 for stress. The DASS anxiety scale correlates 0.81 with the Beck Anxiety Inventory, and the DASS depression scale correlates 0.74 with the Beck Depression Scale. ${ }^{12}$ DASS has previously been used as a valid and reliable measure of depression, anxiety and stress in India.

\section{Measures of functional ability}

The functional ability was measured by the WHO Disability Assessment Schedule 2.0. ${ }^{13}$ The instrument covers six domains: understanding and communicating with the world, moving and getting around, self-care, getting along with people, life activities and participation in society. Scores for each question range from 0 (no difficulty) to 4 (extreme difficulty/can not do). The standardised global score ranges from 0 (non-disabled) to 100 (maximum disability). This measurement has been extensively validated in India and other low- and middleincome countries.

\section{Measures of social cohesion}

Three factors of social cohesion, trust, community participation and safety, were measured using 15 questions. ${ }^{14}$ A composite score was created by summing the overall score to measure social cohesion. The trust was measured using a standardised scale for convenience of interpretation, which had three questions, trust in people in the participants' neighbourhood and trust in people with whom the participants work. Community participation is a standardised scale indicating the frequency of involvement in community activities in the last 12 months. It consists of nine activities such as attending public meetings in which there was discussion of local or school affairs, meeting personally with a community leader, attending any group, club, society, union or organisation meeting, working with people in the neighbourhood to fix or improve something, having friends over to one's home, being in the home of someone who lives in a different neighbourhood, socialising with coworkers outside of work, attending religious services (excluding weddings and funerals) and getting out to attend social meetings, activities, programmes or events or to visit relatives or friends. Perceived safety was measured using a standardised scale, measuring the perception of safety from crime and violence when he or she is alone at home and when walking down his/her street alone after dark. The general social trust was assessed by asking whether or not the participants believe that most people can be trusted. 


\section{Measures of social support network}

Social support networks were measured using the Wenger's social network typologies. Five network typologies were identified based on responses to eight questions on the distance to nearest relative, distance to the nearest child, distance to the nearest sibling, contact frequency with children or relatives, contact frequency with friends in the community, religious involvement and involvement in social groups. ${ }^{15}$ The different typologies measured in the survey include locally integrated social networks, locally self-contained network type, wider community focussed network type, family dependent network type and the private restricted network type.

Locally integrated network type includes close involvement with family members, friends, neighbours and the community. The locally self-contained network type involves a household focussed lifestyle with arm's length relationship with kin, little community activity. The person relies considerably on neighbours. Wider community focussed network type refers to a lack of local family members but has good contact with friends and neighbours. The family dependent network type is characterised by the active involvement of close family members and limited contact with friends and neighbours. The private restricted network type is described as an absence of a close relationship with family, few nearby friends and low levels of community involvement. The Wenger typology has been used in the $10 / 66$ survey ${ }^{16}$ in different countries including India and has been validated elsewhere. ${ }^{17}$

\section{Measures of behavioural risk factors}

The behavioural risk factors studied in the survey include smoking (usage, frequency, years of usage, etc), alcohol consumption (usage, frequency, years of usage, etc), dietary intake (meat, fish, fruits and vegetables, sugar, salt and oil) and physical activity (exercise, activity status). All the questions for the behavioural risk factors of smoking and alcohol consumption were recorded as Yes or No; Yes, representing the presence of a risk factor and No, representing the absence. Dietary consumption of meat and fish were recorded as never, some days, most days or everyday and physical activity were coded as very physically active, fairly physically active, not very physically active and not at all physically active.

\section{Health service utilisation}

Health service utilisation was measured using questions on a visit to the hospital, availability of services from hospitals, the reason for hospitalisation, type of healthcare facility preferred, transportation to the available healthcare facility, out-of-pocket expenditures and so on. The satisfaction of services received from the hospitals was also recorded as very satisfactory, satisfactory, average, not satisfactory or not at all satisfactory.

\section{Measures of cognitive function}

Cognitive function module was introduced in the first follow-up interview in 2019. Four components (memory, verbal fluency, numerical fluency and orientation) of the cognitive function was assessed using a validated set of tools. ${ }^{18}$ Three words (fish, boat, house) was used to assess the immediate and delayed recall (after $2 \mathrm{~min}$ ). For recent memory, the respondents were asked about their breakfast menu in the morning, and the answer was verified with a family member, and for the remote memory, the respondents were asked to provide the name of the present chief ministers and prime minister. Numerical ability was measured by using series subtraction (100 to 7, continuous) and asked them to repeat the days of the week in the reverse order. Orientation to person, place and thing was measured with two simple questions: (a) with whom you had breakfast and (b) the approximate time. Verbal fluency was assessed using the animal naming task. Participants were asked to name as many different animals as possible in $1 \mathrm{~min}$.

\section{Measurement of risk of falls}

The falls risk assessment tool was used to measure the risk of falls. ${ }^{19}$ Falls module was introduced in the follow-up interview for participants aged over 60 years. The module contains two parts: (a) five-item screening questionnaire that covered the history of previous falls, administration of four or more medications, diagnosis of stroke or Parkinson's disease, self-reported difficulties with balance and standing up from a chair without support and (b) six-item questionnaire which measured the type of fall, the reason for the fall, intensity, frequency and altered gait during the fall.

\section{FINDINGS TO DATE}

\section{Chronic disease risk factors network}

Prevention and management of chronic diseases at individual, family and community levels have become a significant target for the government, funders and healthcare service providers in India. The SWADES baseline data reaffirms that chronic diseases such as diabetes and hypertension do not occur in isolation, and they share aetiology common to many other diseases and disorders. ${ }^{20}$ The results indicate that behavioural and social risk factors interact and may produce a synergistic effect on disease progression as well as active treatment(figure 3 ).

\section{Inequalities in health}

In this population, uncontrolled hypertension and diabetes are very common. However, the distribution of uncontrolled chronic conditions was uneven among men and women as well as social position. More specifically, literacy was identified as the most influential factor that was found to be associated with uncontrolled chronic conditions and receiving the diagnosis.

\section{FURTHER DETAILS}

Quality assessment

STROBE (Strengthening the Reporting of Observational Studies in Epidemiology) checklist for cohort studies was 


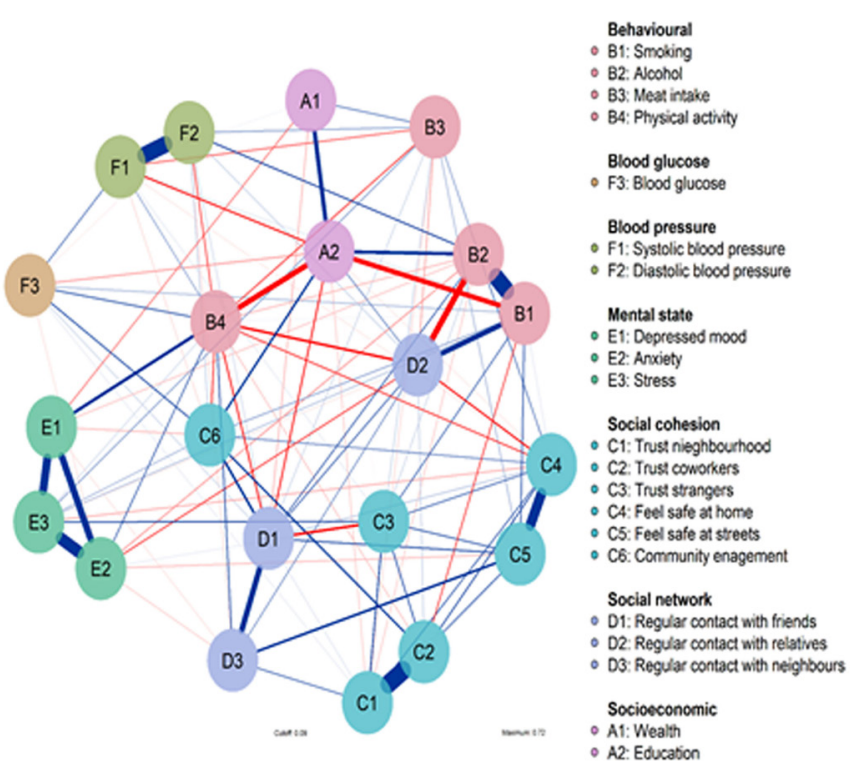

Figure 3 Risk factors network of individual with and without chronic diseases.

used to appraise the paper and its findings are enclosed as the online supplementary file.

\section{STRENGTH AND LIMITATIONS}

The SWADES cohort is not representative of the Kerala population. However, as this 10 years, longitudinal study of community family cohort, the direction of causation for a range of biological, psychological, behavioural and social factors, along with intergenerational exposure, can be investigated. The main strengths of the study are as follow: (1) data were collected using validated tools suitable for the study population, (2) trained interviewers administered all instruments and (c) high response rate.

\section{Author affiliations}

${ }^{1}$ Social Work, Rajagiri College of Social Sciences, Cochin, Kerala, India

${ }^{2}$ Rajagiri International Centre for Consortium Research Social Care (ICRS), Rajagiri

College of Social Sciences, Cochin, Kerala, India

${ }^{3} 12-11-1445 / 1$, Boudha Nagar, Warasiguda, Public Health Researcher, Secunderabad, Telangana, India

${ }^{4}$ Manashanthi Counselling, Research and Training Centre, Highlands, Mangalore, Mangalore, Karnataka, India

${ }^{5}$ Neurology, The Voluntary Health Services Hospital, Chennai, Tamil Nadu, India ${ }^{6}$ Department of Psychiatric Social Work, NIMHANS, Bangalore, Karnataka, India ${ }^{7}$ Department of Ageing and Life Course, WHO, Geneve, GE, Switzerland ${ }^{8}$ Institute of Psychiatry, Psychology and Neurosciences, King's College London, London, UK

Acknowledgements The authors wish to thank the academic contributors Martin Webber, Professor, Department of Social Policy and Social Work, University of York, UK; Roz Austin, Research Associate, Department of Social Policy and Social Work, University of York, UK; Lynette Joubert, University of Melbourne, Australia; Jacques Joubert, Professor, University of Melbourne, Australia; Jeemon Panniyammakkal, Assistant Professor, Sri Chithira Tirunal Institute of Science and Technology, Trivandrum, Kerala, India; Jennifer Harrison, Assistant Professor, College of Health and Human Services, Western Michigan University, Kalamazoo, USA and Meredith Fendt-Newlin, Global Mental Health Consultant, Geneva Area, Switzerland. We acknowledge the support of community health workers and thank all the participants who were part of the data collection.
Contributors All of the authors worked collectively to develop the protocols and methods described in this paper. SMD led the research group as lead principle investigator and wrote the first draft of the manuscript with LN. AMB and LS conducted the data analysis, performed the literature review and contributed to writing of the manuscript. RS, SP, KG and BMV were part of the research group and they provided technical inputs for the development of the survey instruments and implementation protocol. ATJ conceptualised and designed the SWADES longitudinal study in collaboration with SMD. All authors read and approved the final manuscript.

Funding The initial funding for the SWADES survey is provided by University Grant Commission, New Delhi, India (Project reference number - UGCUKIERI-2016-17-089, F. N0. 184-3/2017 (IC)) and Rajagiri International Centre for Consortium Research in Social Care, Rajagiri College of Social Sciences (Autonomous), Kerala, India.

Competing interests None declared.

Patient consent for publication Not required.

Ethics approval The study was approved by Rajagiri Hospital Institutional Ethics Committee (Study Reference Number: RAJH 18003).

Provenance and peer review Not commissioned; externally peer reviewed.

Data availability statement Data are available upon reasonable request. For research collaboration, please contact the corresponding author.

Open access This is an open access article distributed in accordance with the Creative Commons Attribution Non Commercial (CC BY-NC 4.0) license, which permits others to distribute, remix, adapt, build upon this work non-commercially, and license their derivative works on different terms, provided the original work is properly cited, appropriate credit is given, any changes made indicated, and the use is non-commercial. See: http://creativecommons.org/licenses/by-nc/4.0/.

ORCID iD

Saju M D http://orcid.org/0000-0002-6188-9267

\section{REFERENCES}

1 GBD 2017 Mortality Collaborators. Global, regional, and national age-sex-specific mortality and life expectancy, 1950-2017: a systematic analysis for the global burden of disease study 2017. Lancet 2018;392:1684-735.

2 GBD 2017 Causes of Death Collaborators. Global, regional, and national age-sex-specific mortality for 282 causes of death in 195 countries and territories, 1980-2017: a systematic analysis for the global burden of disease study 2017. Lancet 2018;392:1736-88.

3 James SL, Abate D, Abate KH, et al. Global, regional, and national incidence, prevalence, and years lived with disability for 354 diseases and injuries for 195 countries and territories, 1990-2017: a systematic analysis for the global burden of disease study 2017. Lancet 2018;392:1789-858.

4 India State-Level Disease Burden Initiative Collaborators. Nations within a nation: variations in epidemiological transition across the states of India, 1990-2016 in the global burden of disease study. Lancet 2017;390:2437-60.

5 Dudley L, Garner P. Strategies for integrating primary health services in low- and middle-income countries at the point of delivery. Cochrane Database Syst Rev 2011;7:CD003318.

6 Patel V, Chatterji S, Chisholm D, et al. Chronic diseases and injuries in India. Lancet 2011;377:413-28.

7 Beaglehole R, Epping-Jordan J, Patel V, et al. Improving the prevention and management of chronic disease in low-income and middle-income countries: a priority for primary health care. Lancet 2008;372:940-9.

8 Hébert R, Durand PJ, Dubuc N, et al. PRISMA: a new model of integrated service delivery for the frail older people in Canada. Int $J$ Integr Care 2003;3:e08.

9 D'Sa L, Senaratne N, Woodcock-Smith J, et al. Evaluation of the Omron HEM-907 automated blood pressure device: comparison with office and ambulatory blood pressure readings. Hypertens Res 2019;42:52-8.

10 Chopra P, Kumar TSS. Correlation of glucose level among venous, gingival and finger-prick blood samples in diabetic patients. J Indian Soc Periodontol 2011;15:288-91.

11 Brown TA, Chorpita BF, Korotitsch W, et al. Psychometric properties of the depression anxiety stress scales (DASS) in clinical samples. Behav Res Ther 1997;35:79-89. 
12 Lovibond PF, Lovibond SH. The structure of negative emotional states: comparison of the depression anxiety stress scales (DASS) with the Beck depression and anxiety inventories. Behav Res Ther 1995;33:335-43.

13 WHO. Measuring health and disability : manual for WHO Disability Assessment Schedule WHODAS 2.0 ed. T.B. Üstün. Geneva: World Health Organization, 2010.

14 Hsieh N, Security E. Economic security, social cohesion, and depression disparities in post-transition societies: a comparison of older adults in China and Russia. J Health Soc Behav 2015;56:534-51.

15 Wenger GC. A network typology: from theory to practice. J Aging Stud 1991;5:147-62.

16 Thiyagarajan JA, Prince M, Webber M. Social support network typologies and health outcomes of older people in low and middle income countries--a 10/66 Dementia Research Group populationbased study. Int Rev Psychiatry 2014;26:476-85.

17 Stephens C, Alpass F, Towers A, et al. The effects of types of social networks, perceived social support, and loneliness on the health of older people: accounting for the social context. J Aging Health 2011;23:887-911.

18 Arokiasamy P BD, Lee J. Longitudinal aging study in India: vision, design, implementation, and preliminary findings. Aging in Asia: Findings From New and Emerging Data Initiatives, 2012. https:// www.ncbi.nlm.nih.gov/books/NBK109220/

19 Nandy S, Parsons S, Cryer C, et al. Development and preliminary examination of the predictive validity of the falls risk assessment too (Frat) for use in primary care. J Public Health 2004;26:138-43.

20 Singh P, Khullar S, Singh M, et al. Diabetes to cardiovascular disease: is depression the potential missing link? Med Hypotheses 2015;84:370-8. 